\title{
STUDY OF SOLAR BASED VERTICAL FARMING SYSTEMS WITH RAY- TRACED DAYLIGHTING ANALYSIS AND VISUALIZATIONS
}

\begin{tabular}{|c|c|}
\hline \multicolumn{2}{|c|}{$\begin{array}{c}{ }^{1} \text { School of Mechanical and Aerospace Engineering, Nanyang Technological University, } \\
\text { 639798, Singapore } \\
\otimes_{\text {mykng@ntu.edu.sg }} \\
\text { ps://doi.org/10.34302/crpjfst/2020.12.4.3 }\end{array}$} \\
\hline $\begin{array}{l}\text { Article history: } \\
\text { Received: } \\
\quad 10 \text { March } 2020 \\
\text { Accepted: } \\
\quad 25 \text { November } 2020 \\
\text { Keywords: } \\
\text { Urban food security; } \\
\text { Vertical farm (VF); } \\
\text { Ray tracing design; } \\
\text { Solar irradiance; } \\
\text { Ray-trace; } \\
\text { Sunlight modelling. }\end{array}$ & 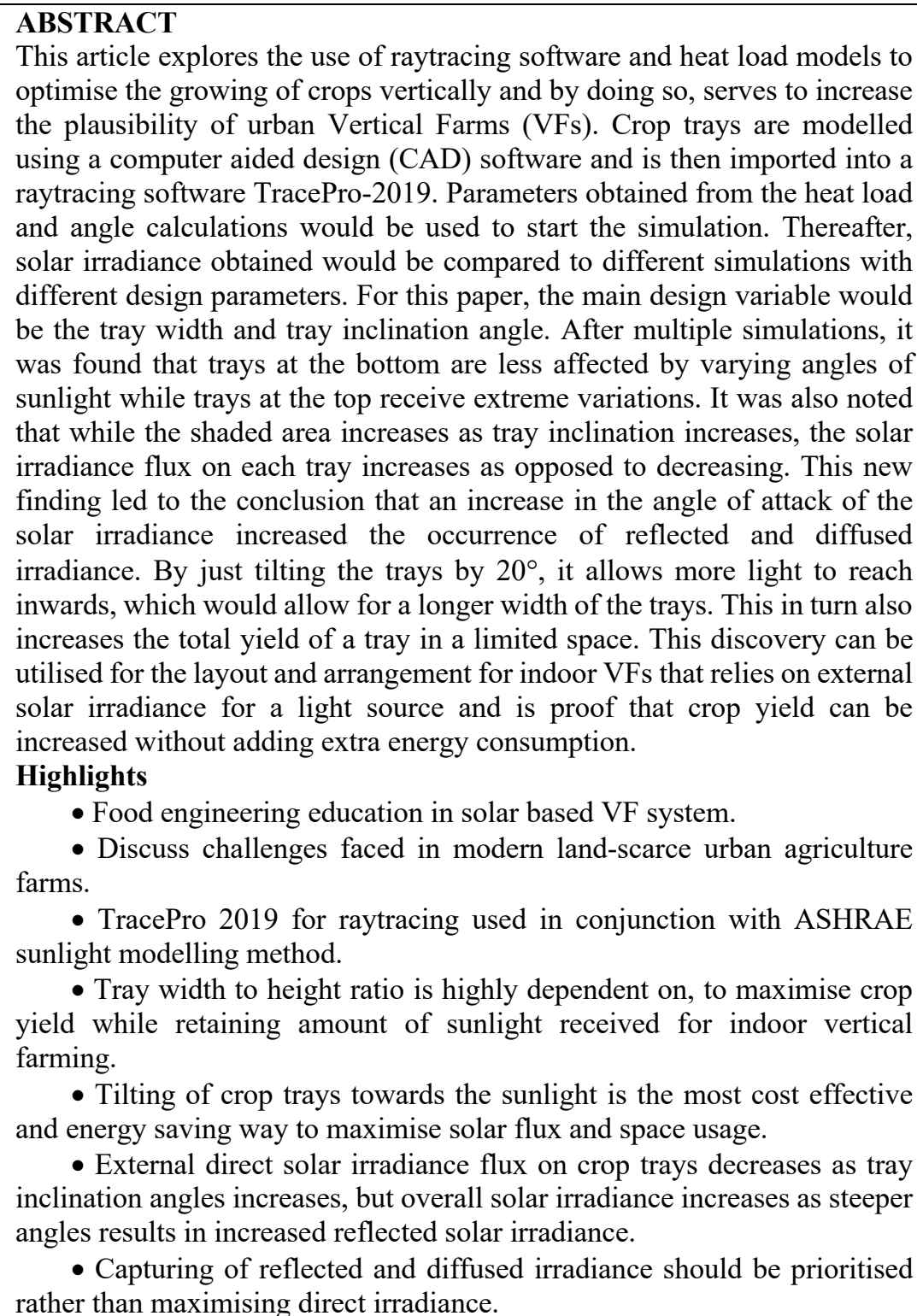 \\
\hline
\end{tabular}




\section{Introduction}

Traditionally, the conventional farming method was a favoured approach to produce crops in large quantities. It is a farming system that requires the use of synthetic chemical fertilisers, pesticides, herbicides, heavy irrigation, and other continual inputs for crops production. This method, which is also commonly known as industrial agriculture, boasts a high crop yield at the expense of being energy and resource extensive. In Singapore, due to its limited land space, a more innovative and energy efficient farming system will be needed to enable us to grow as much of our own supply of crops.

Urban Vertical Farming (VF) is no new idea and has been actively researched on in many countries. It provides us with a solution when it comes to growing our own crops in a limited area as theoretically, a VF is only limited by how high the building can be built. Apart from solving the land issue, there are many more advantages that comes with it. As a start, water losses would be kept to a minimum as the usage of water is controlled and transpired water can be reused, further saving the usage. No pesticides would be required as in a controlled environment, there would be no pests to damage the crops, allowing the crops to grow more organically. The usage of artificial lighting also mean that crops can grow throughout the year and will not be hindered by weather, allowing maximum crop yield. Dr. Despommier of Columbia University believes that the ways indoor farming should be done is through tall multi-storey structures. He claims that one VF with an architectural footprint of one square city block and rising to 30 stories could provide enough nutrition to comfortably accommodate the needs of 10,000 people with the currently available technologies (Despommier and Ellingsen, 2008). In addition, it is stated in a research that VF will lower overall carbon dioxide output by $67-92 \%$ as compared with greenhouse gases, which is in line with Singapore's Clean and Green campaign (Graamansa et al, 2018).

However, one of the more prominent issues highlighted for $\mathrm{VF}$ is the amount of energy required to maintain the environment within the levels. A lot of energy would be required to produce artificial lighting for the plants as sunlight would not be ample due to design constraints (Kalantari et al, 2017). Energy would also be required by air pumps to maintain the temperature and humidity of the room, to ensure that the plant can grow in the optimum condition. A possible way to reduce the energy consumption would be to find a way in which solar irradiance can still be utilized, by optimizing the reflectivity of the surfaces within the farm, adopting an 'open' concept by using glass walls instead of opaque structural walls, or simply by the arrangement of the plant trays. Heat from the irradiation of the Sun could be harnessed to heat up floors that require the extra energy to maintain the set temperature. However, the presence of an external heat source combined with waste heat from the operating systems may prove to be counterproductive instead.

The aim of this paper would be to identify how different tray placement designs would affect the solar irradiance received. The variable design parameters are the position, width, angle of tilt of the trays with respect to the windows and reflectivity of the surfaces within the room. These designs are supported by a modelling of the Sun's position with respect to the rooms at various times of the day to observe the pattern of irradiance, such that a maximum flux can be captured in a day. A ray tracing software will be utilized to generate accurate data for the charts. An estimation of the ratio of heat energy contributed by the Sun to the waste heat energy generated by the operating systems of a VF would also be generated, as means to determine if urban VF should adopt an 'open' concept.

\subsection{Motivation}

Singapore is a small city with very limited land available for agriculture and $90 \%$ of the food we consume are imported from other countries. There is a growing demand in fresher food and food grown locally could be one of the methods to solve this. Locally produced food would also be cheaper and more affordable due 
to the reduction in costs from the transportation process. We would also need to cultivate our own crops as a backup to increase the food security of Singapore particularly for the Covid19 lockdown periods.

As Singapore progresses to be a smart and self-sustaining nation, having an energy efficient farming system here may serve as a potential case study for other countries to learn from, due to the compact nature of our landscape. This can boost our country's presence worldwide in the utilisation of VF systems. So far, there has also been a lack of research that evaluates the energy consumed by VF locally and the best possible way for plant arrangement. To ensure that urban VF becomes a suitable and sustainable way of farming in Singapore, it is crucial to gain insights from various related research papers and experienced organisations. Therefore, this article may serve to provide some groundwork for this area of study.

\section{Materials and methods}

Before we can state the assumptions for the simulation parameters, we would first need to find out the total energy coming from the Sun throughout the year. As we know, the Sun radiates a tremendous amount of energy throughout the year and it contributes to most of the heat generation in a system. The position and angle of the sun with respect to the simulation plays an important role as it determines the angle at which the rays strike the surface, which in turn affects the amount of energy received and transferred into the room.

These approaches will be used in conjunction to derive the total energy received by the VF and to subsequently determine the suitability of the design.

\subsection{Mathematical Evaluation (with ASHRAE)}

A comprehensive set of calculations would be required to evaluate the results required for the actual simulation of the VF design. The approach is split into 6 steps:

Determination of Solar Declination Angle (SDA) in Singapore as test example

Determination of Solar Incidence Angle (SIA) to the normal of the walls
Evaluation of Total Solar Irradiation per square unit on the walls

Evaluation of Total Heat Transfer through the walls into the room

Addition of both latent and sensible heat within a room to determine cooling load

Energy cost analysis

For the determination of the SDA and SIA, the ASHRAE Model would be used to obtain their values, respectively. This alternative eliminates the need for an actual equipment, which is highly cost. This model's algorithm provides a simple method to predict the position of the Sun relative to Singapore and even allows for rough estimations of the solar irradiation (Abouhashish, 2017; Yadav and, Chandel, 2014). Also, ASHRAE Model allows for the estimation of values at any time of the year. However, if this study is to be continued for further refinement and research, it would be necessary to do more literature review for the determination of the best model (e.g. Perez), or getting an equipment to generate a data log for Solar Irradiation on Singapore.

The purpose of doing a manual calculation of heating load is to obtain the irradiance energy which is required by Trace Pro 2019 software. Those energy readings can then be reflected on the simulation parameters in TracePro to obtain respective flux on the tray readings, which in turn can be converted to photometric units. The values are obtained for any single time or date in the year and the location can be customizable as mentioned above.

\subsection{Trace Pro 2019}

This software is a commercial optical engineering software program used for designing and analysing optical and illumination systems. The program's graphical user interface (GUI) is 3D CAD-based creating a virtual prototyping environment to perform software simulation before manufacture. Users can import models created with SolidWorks into TracePro to simulate lit appearance of illumination or lighting systems and trace bitmap images through optical systems to check for uniformity. Thermal energy effects can also be captured by this code. 
TracePro is used here to determine energy distributions on the tray surfaces and tracking of the volume flux in the control volume. Through TracePro, a light source will be created and will mimic the properties of Sunlight entering a room. It also plays a key role in the optimisation of the room design, ranging from the distance of trays from the windows, to the height in between each tray including the angle of orientation for the trays.

The results generated by TracePro come in the form of both visual data and numerical data and they can be exported out with ease.

\section{Results and discussions}

\subsection{Determination of Solar Angle of Declination $(\boldsymbol{\delta})$}

The Solar Angle of Declination is an angle that is dependent on the date of the year Earth is at. The declination of the Sun is the angle between the equator and a line drawn from the centre of the Earth to the centre of the Sun. It follows the relation as shown below:

$$
\delta=23.45^{\circ} \times \sin \left[\frac{360(284+n)}{365}^{\circ}\right]
$$

\subsubsection{Determination of Solar Altitude Angle ( $\beta$ ) \& Solar Azimuth $(\varnothing)$}

The Solar Altitude Angle $(\beta)$ is an angle that is between the Sun's rays and the horizontal of a point. It is used to model the vertical angle of the Sun's ray entering the control volume. It depends on three main parameters, the Hour Angle (h), Latitude (l) of point and Solar Angle of Declination $(\delta)$. The hour angle is also dependant on the solar time $t_{s}$, e.g. $(1 \mathrm{pm}=13$ and $2 \mathrm{pm}=14$ ) as below:

$$
\begin{gathered}
h=15\left(t_{s}-12\right) h r s \\
\sin \beta=\cos l \cosh \cos \delta+\operatorname{sinl} \sin \delta
\end{gathered}
$$

The Solar Azimuth $(\varnothing)$ is required to determine the angle between the projection of the Sun's ray on the horizontal plane and the south direction. It will be useful in modelling the horizontal angle of the Sun's ray entering the control volume.

$$
\cos \emptyset=\frac{\sin \beta \sin l-\sin \delta}{\cos \beta \cos l}
$$

\subsubsection{Evaluation of Total Solar Irradiation per square units on the walls}

The Total Solar Irradiation entering the control volume is simply the addition of the Normal Direct Irradiation ( $\left.G_{D}\right)$, Diffuse Radiation $\left(G_{d \theta}\right)$ and Reflected Radiation $\left(G_{R}\right)$. Their formulas are given as:

$$
\begin{gathered}
G_{D}=C_{N} * A e^{-\left(\frac{B}{\sin \beta}\right)} * \cos \theta \\
G_{d \theta}=\frac{C * A e^{-\left(\frac{B}{\sin \beta}\right)} * F_{S}}{C_{N}{ }^{2}}
\end{gathered}
$$

$G_{R}$

$=\left[C_{N} * A e^{-\left(\frac{B}{\sin \beta}\right)} * \sin \beta\right.$

$\left.+\frac{C * A e^{-\left(\frac{B}{\sin \beta}\right)} * F_{S}}{C_{N}{ }^{2}}\right] * \rho * F_{S}$

where

$C_{N}$ is Coefficient of Clearness of Sky (Assumed as 1)

$A$ is the Apparent Solar Radiation taken from the ASHRAE Table 1.

$B$ and $C$ are correction factors from ASHRAE Table

$\theta$ is $\cos ^{-1} \sin \beta$

$F_{S}$ is the view factor $(0.5$ for the current control volume)

$\rho$ is the reflectance of the object ( 0.2 for the current control volume)

Table 1. ASHRAE solar data (2001)

EOT, Declination, Extraterrestrial Solar Data Tables (ASHRAE 2001)

\begin{tabular}{|c|c|c|c|c|c|c|}
\hline Month & $\mathrm{G}_{\mathrm{sc}} \mathrm{W} / \mathrm{m}^{2}$ & EOT $\mathrm{min}$ & $\delta^{\circ}$ & $\mathrm{A} \mathrm{W} / \mathrm{m}^{2}$ & $\mathrm{~B}$ & $\mathrm{C}$ \\
\hline Jan & 1416 & -11.2 & -20.0 & 1230 & 0.142 & 0.058 \\
\hline Feb & 1401 & -13.9 & -10.8 & 1215 & 0.144 & 0.060 \\
\hline Mar & 1381 & -7.5 & 0.0 & 1186 & 0.156 & 0.071 \\
\hline Apr & 1356 & 1.1 & 11.6 & 1136 & 0.180 & 0.097 \\
\hline May & 1336 & 3.3 & 20.0 & 1104 & 0.196 & 0.121 \\
\hline Jun & 1336 & -1.4 & 23.45 & 1088 & 0.205 & 0.134 \\
\hline Jul & 1336 & -6.2 & 20.6 & 1085 & 0.207 & 0.136 \\
\hline Aug & 1338 & -2.4 & 12.3 & 1107 & 0.201 & 0.122 \\
\hline Sep & 1359 & 7.5 & 0.0 & 1151 & 0.177 & 0.092 \\
\hline Oct & 1380 & 15.4 & -10.5 & 1192 & 0.160 & 0.073 \\
\hline Nov & 1405 & 13.8 & -19.8 & 1221 & 0.149 & 0.063 \\
\hline Dec & 1417 & 1.6 & -23.45 & 1233 & 0.142 & 0.057 \\
\hline
\end{tabular}




\subsection{Results \& Findings from Trace Pro 2019} 3.2.1.Model Design A with 1:2 Height to Width Ratio (@0800hr)

Fig. 1 and Table 2 presents the basic schematic view and design variables \& parameters for our models used.

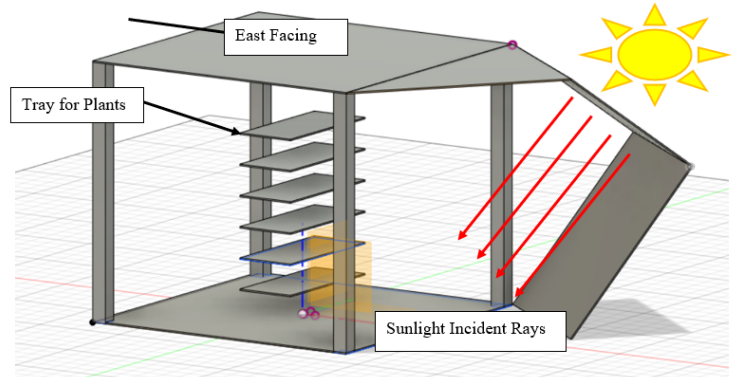

Figure 1. Model A 1:2 Height to Width Ratio@0800hrs

Table 2. Design A Variables \& Parameters used

\begin{tabular}{|c|l|}
\hline \multicolumn{2}{|c|}{ Tray for Plants } \\
\hline Width & $80 \mathrm{~mm}$ \\
\hline Length & $180 \mathrm{~mm}$ \\
\hline Thickness & $2 \mathrm{~mm}$ \\
\hline Distance in between & $40 \mathrm{~mm}$ \\
\hline Distance from Window & $160 \mathrm{~mm}$ \\
\hline \multicolumn{2}{|c|}{ Base of Floor } \\
\hline Length & $400 \mathrm{~mm}$ \\
\hline Width & $400 \mathrm{~mm}$ \\
\hline Height & $350 \mathrm{~mm}$ \\
\hline \multicolumn{2}{|c|}{ Sun Ray } \\
\hline Emission Type & Irradiance (Visible Light \\
& Spectrum) \\
\hline Power & 737.84 W/m² \\
\hline Solar Altitude Angle & 27.93 Degrees \\
\hline Solar Azimuth Angle & 25.65 Degrees \\
\hline
\end{tabular}

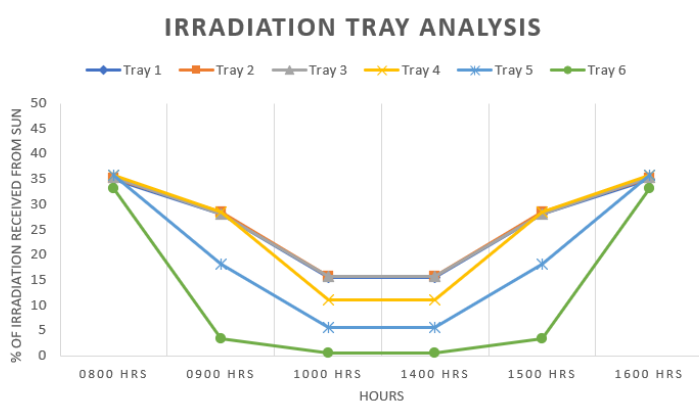

Figure 2. Irradiation Tray Analysis (Design A)

\subsubsection{Shaded Area for Design A}

To maximise space usage, the space between two trays is kept at 40 units as lettuce only grow to an average height of 12 inches. Coupled with the sunlight declination angle, part of the tray will be shaded from direct irradiance. The shaded area can be related to the distance between each tray by Eq. (8) as shown in Fig. 3.

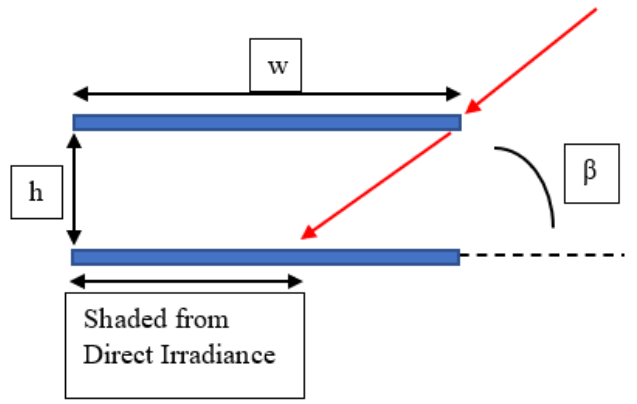

Figure 3. Schematic Side view of Trays layout

$$
\begin{aligned}
& \left(1-\left(\frac{h}{w}\right) *\left(\frac{1}{\tan \beta}\right)\right) * 100 \% \\
& =\% \text { area shaded }
\end{aligned}
$$

As the solar declination angle increases throughout the day, the percentage of shaded area on each tray are increased. This reflects the steady decrease of irradiance flux on each of the tray surfaces as seen from Fig. 2. From Eq. 8, it can be intuitively inferred that the more the percentage of shaded area, the lesser the irradiance flux on the tray surface (Table 3).

Table 3. Average Flux Decrease (Design A)

\begin{tabular}{|c|c|c|c|}
\hline & $0800 \mathrm{hrs}$ & $0900 \mathrm{hrs}$ & $1000 \mathrm{hrs}$ \\
\hline Solar Declination Angle & 27.93 & 41.21 & 53.61 \\
\hline Average \% Flux & 35 & 22 & 11 \\
\hline Average Flux Decrease & \multicolumn{3}{|c|}{ Approx. 12\% per Hour } \\
\hline
\end{tabular}

Table 4. Photosynthetic Proton Flux Density (PPFD) (Design A)

\begin{tabular}{|c|c|c|c|}
\hline S/N & $\begin{array}{c}\text { Average Flux } \\
\text { Received } \\
(\mathrm{W})\end{array}$ & $\begin{array}{c}\text { Average Flux } \\
\text { Received per metre } \\
\left(\frac{W}{m^{2}}\right)\end{array}$ & $\begin{array}{c}\text { PPFD } \\
\left(\frac{\mu \text { mol }}{\mathrm{sm}^{2}}\right)\end{array}$ \\
\hline Tray 1 & 2.75 & 191 & 447 \\
\hline Tray 2 & 2.78 & 193 & 451.6 \\
\hline Tray 3 & 2.77 & 192.4 & 450.2 \\
\hline Tray 4 & 2.65 & 184.3 & 431.3 \\
\hline Tray 5 & 2.1 & 146.1 & 341.9 \\
\hline Tray 6 & 1.32 & 91.4 & 213.9 \\
\hline
\end{tabular}

From Table 4, the PPFD values obtained were suitable for the growing of lettuce, which means indoor growing of plants near to the 
window would be possible with natural light alone.

It can also be inferred from Fig. 2 that the irradiance flux on the lower trays changes less drastically as compared to trays closer to the top. The drop in flux on each tray at different time is also more stable on the lower trays as compared to those at the top. It would be suggested that the trays be placed as close as possible to the windows.

At higher solar declination angles, trays 5 and 6 showed a drastic change in irradiance as compared to the other trays. This suggests that trays closer to the top are more sensitive to changes in the angle of declination and if likely, should be replaced by trays perpendicular to the floor (see Fig. 4).

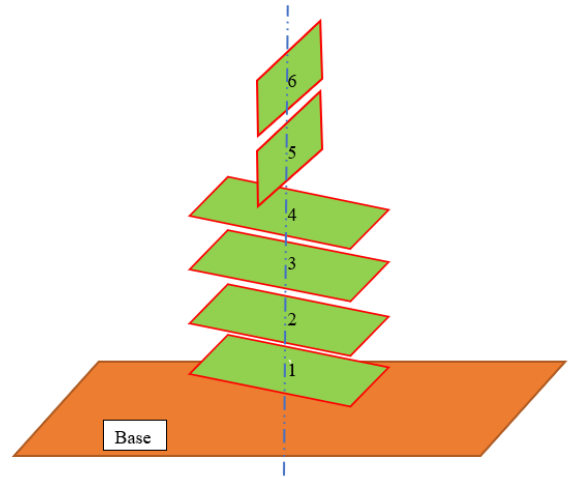

Figure 4. Rough illustration of Trays Layout 3.2.3.Model Design B with 1:3 Height to Width Ratio (@0800hr)

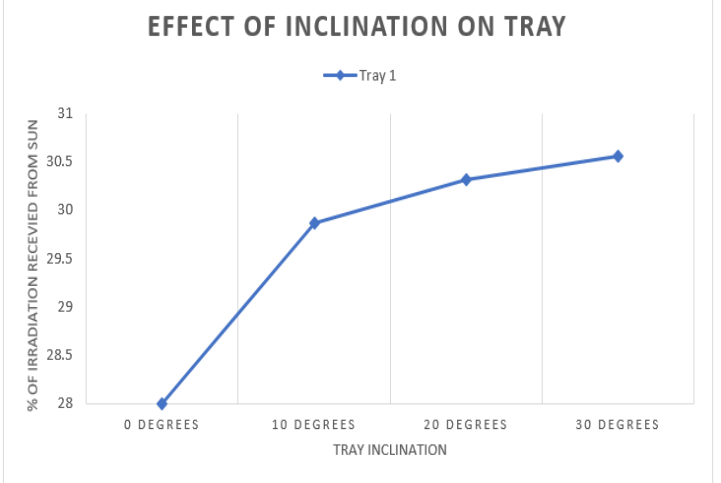

Figure 5. Relationship between Irradiance Flux Received to Angle of Inclination on Tray 1 (Design B)
IRRADIATION TRAY ANALYSIS @ 0 DEGREES
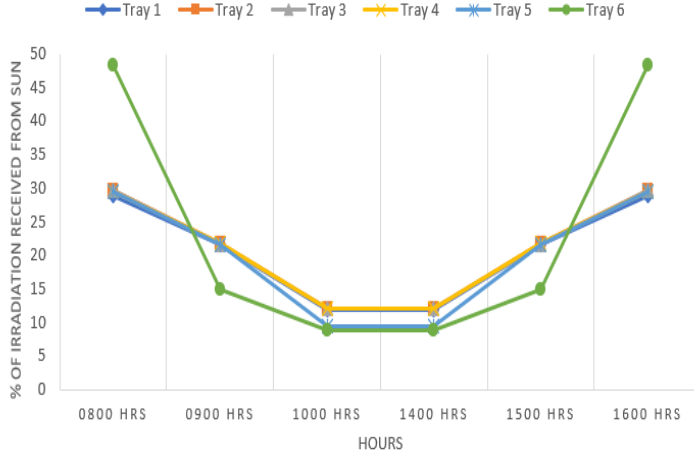

Figure 6. Irradiation Tray Analysis @ $0^{\circ}$ (Design B)

IRRADIATION TRAY ANALYSIS @ 10 DEGREES

$\rightarrow$ Tray 1 -Tray 2 \#-Tray $3-$-Tray 4 \#-Tray $\rightarrow$-Tray 6

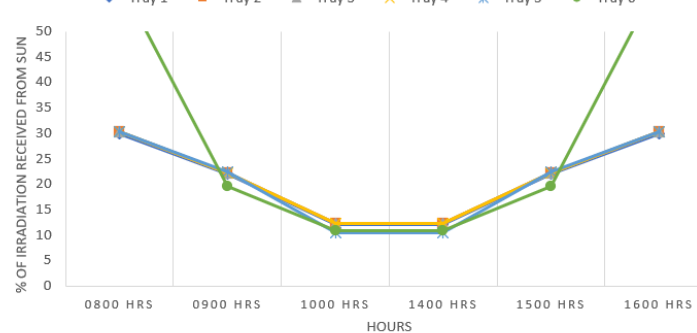

Figure 7. Irradiation Tray Analysis @ 10 (Design B)

IRRADIATION TRAY ANALYSIS @ 20 DEGREES

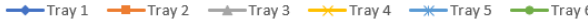

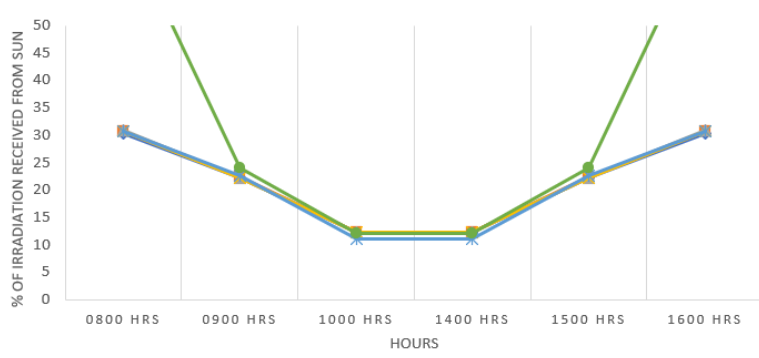

Figure 8. Irradiation Tray Analysis @ 20 (Design B)

Since the average lettuce requires a Photosynthetic Proton Flux Density (PPFD) of $196.8 \frac{\mu \mathrm{mol}}{\mathrm{sm}^{2}}$, the results in Table 5 reveal that there is an adequate amount of natural sunlight to sustain its growth.

Table 5. Photosynthetic Proton Flux Density (PPFD) of Trays @ 20 Tilt (Design B) 


\begin{tabular}{|c|c|c|c|}
\hline S/N & $\begin{array}{c}\text { Average } \\
\text { Flux } \\
\text { Received } \\
(\mathrm{W})\end{array}$ & $\begin{array}{c}\text { Average Flux } \\
\text { Received per } \\
\text { metre }\left(\frac{W}{m^{2}}\right)\end{array}$ & $\begin{array}{c}\text { PPFD } \\
\left(\frac{\mu m o l}{s m^{2}}\right)\end{array}$ \\
\hline Tray 1 & 3.4 & 157.4 & 368.3 \\
\hline Tray 2 & 3.45 & 159.7 & 373.7 \\
\hline Tray 3 & 3.44 & 157.4 & 368.3 \\
\hline Tray 4 & 3.44 & 157.4 & 368.3 \\
\hline Tray 5 & 3.35 & 155.1 & 363 \\
\hline Tray 6 & 4.8 & 222.2 & 520 \\
\hline
\end{tabular}

Comparing the values between Tables 4 and 5, Tray 6 from Design B received an equivalent of 520 PPFD whereas Design A only received significantly lesser at 213.9 PPFD. A small portion of the increase can be attributed to the increase in tray width on Design B, but a large portion of it was caused by the tilting of the trays. The tilting combined with no shading, simply allowed Tray 6 at the top to be exposed to a higher irradiance flux from the sun.

\subsection{Shaded Area for Design $B$}

For design $\mathrm{B}$, due to the addition of inclination and width of trays (Fig. 9), it is expected that the shaded area of the trays beneath will be affected more. This means that intuitively there would be smaller amount of irradiance flux on the surface of the trays, resulting in smaller values.

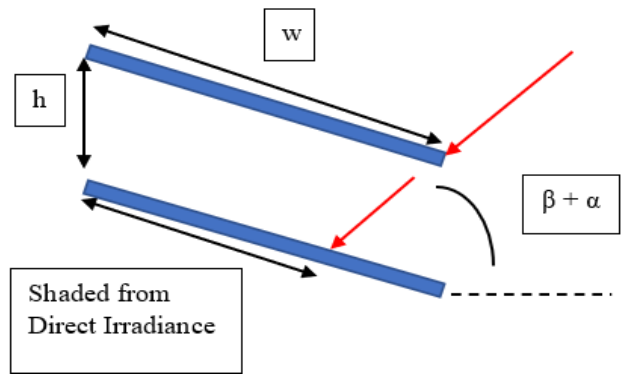

Figure 9. Schematic Side view of Trays layout with an extra inclination angle $\alpha$

$$
\begin{array}{r}
\left(1-\left(\frac{h}{w}\right) *\left(\frac{1}{\tan (\beta+\alpha)}\right)\right) * 100 \% \\
=\% \text { area shaded }
\end{array}
$$

Table 6. Relationship between Angle of Inclination and Shaded Area of Trays (Design B)

\begin{tabular}{|c|r|r|r|}
\hline $\begin{array}{c}\text { Angle of } \\
\text { Inclination } \\
\left({ }^{\circ}\right)\end{array}$ & Hour (hrs) & Angle $\left(^{\circ}\right)$ & Shaded Area \\
\hline 0 & 0800 & 27.93 & $37.12 \%$ \\
\hline
\end{tabular}

\begin{tabular}{|c|c|c|c|}
\hline \multirow{3}{*}{} & 0900 & 41.21 & $61.94 \%$ \\
\cline { 2 - 4 } & 1000 & 53.61 & $75.43 \%$ \\
\hline \multirow{3}{*}{10} & 0800 & 27.93 & $57.23 \%$ \\
\cline { 2 - 4 } & 0900 & 41.21 & $73.21 \%$ \\
\cline { 2 - 4 } & 1000 & 53.61 & $83.46 \%$ \\
\hline \multirow{3}{*}{20} & 0800 & 27.93 & $69.91 \%$ \\
\cline { 2 - 4 } & 0900 & 41.21 & $81.68 \%$ \\
\cline { 2 - 4 } & 1000 & 53.61 & $90.20 \%$ \\
\hline
\end{tabular}

This is supported by the data obtained in Table 6 , with the whole tray almost in the shade at $20^{\circ}$ inclination $1000 \mathrm{hrs}$. However, from Table 7 and Figs. 5 to 8, it can be interpreted that increasing the angle of inclination of the trays increases the irradiance flux on the trays. It can be argued that with the increase of angle, the exposed surface has a larger angle normal to the irradiance which results in the higher calculated flux. On closer inspection what can be noticed is that the 'red' region (Figs. $10 \& 11$ ) of the trays reduces in area - which is supported by the larger shaded area.

On the other hand, there is an increase in the reflected and diffuse irradiance that is casted normal to the shaded area of the trays. This phenomenon is also seen on the trays at other timings of the day, which further reinforces the theory that a higher tilt angle can be utilised effectively to bounce off irradiance to the unshaded areas of the tray. This suggests that design B can be likely adopted for above ground 'open' VF to optimize the growing of crops.

The increase in flux on each tray is however not as significant as expected, which can be attributed to the simulation parameter being used. The reflectivity of the tray surface was set to 0.1 so as to set the contrast between the area under the direct irradiance and the parts affected by reflected irradiance. Therefore, it is more important to focus on the relative changes than the actual value itself as the values act more as an extremely conservative result. It is notable that as the angle of inclination increases, the bottom 4 trays tend to receive almost the same amount of flux regardless of their position relative to the ground. Tray 6 is more heavily affected by changes in the inclination. 

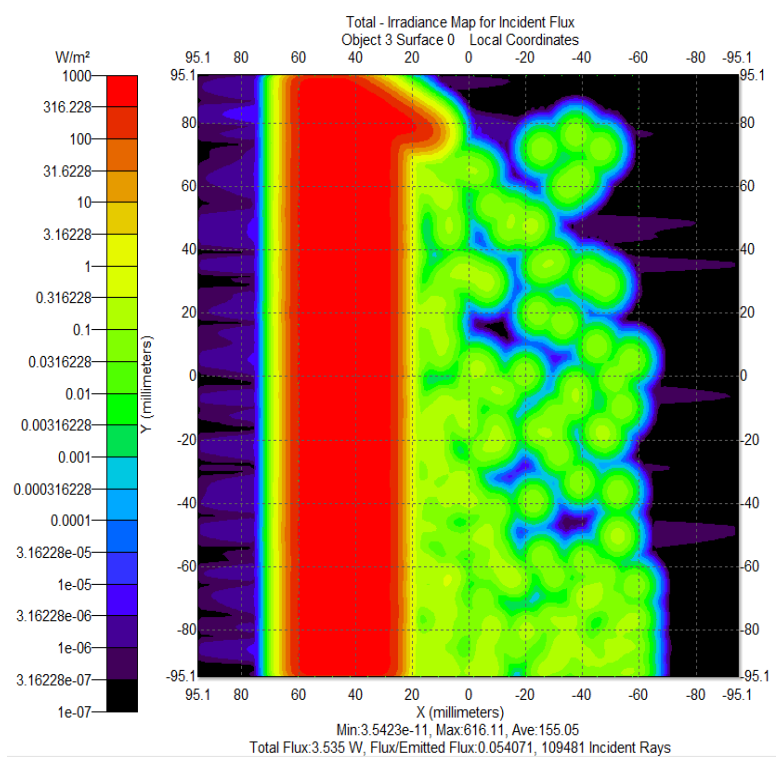

Figure 10. Total irradiance map for incident flux of Tray $3 @ 0900 \mathrm{hrs} 10^{\circ}$ Incline
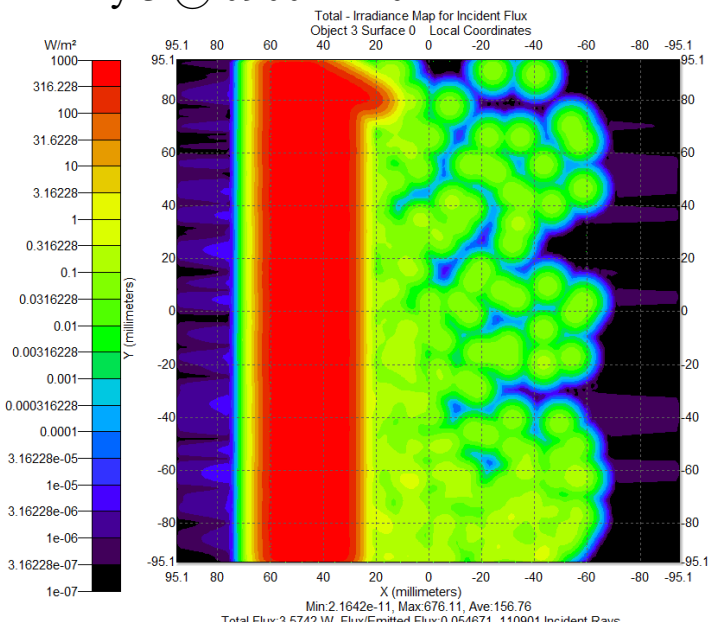

Figure 11. Total irradiance map for incident flux of Tray $3 @ 0900 \mathrm{hrs} 20^{\circ}$ Incline

Table 7. $0^{\circ}$ Inclination, $10^{\circ}$ Inclination and $20^{\circ}$ Inclination Comparison

\begin{tabular}{|c|c|c|c|}
\hline $\mathbf{0}^{\circ}$ & $0800 \mathrm{hrs}$ & $0900 \mathrm{hrs}$ & $1000 \mathrm{hrs}$ \\
\hline $\begin{array}{c}\text { Solar } \\
\text { Declination } \\
\text { Angle }\end{array}$ & 27.93 & 41.21 & 53.61 \\
\hline $\begin{array}{c}\text { Average \% } \\
\text { Flux }\end{array}$ & 32.5 & 20.6 & 11.1 \\
\hline $\begin{array}{c}\text { Average Flux } \\
\text { Decrease }\end{array}$ & \multicolumn{3}{|c|}{ Approx. 10.7\% per Hour } \\
\hline $\mathbf{1 0}^{\circ}$ & $0800 \mathrm{hrs}$ & $0900 \mathrm{hrs}$ & $1000 \mathrm{hrs}$ \\
\hline $\begin{array}{c}\text { Solar } \\
\text { Declination } \\
\text { Angle }\end{array}$ & 27.93 & 41.21 & 53.61 \\
\hline $\begin{array}{c}\text { Average \% } \\
\text { Flux }\end{array}$ & 35.2 & 21.8 & 11.7 \\
\hline
\end{tabular}

\begin{tabular}{|c|c|c|c|}
\hline $\begin{array}{c}\text { Average Flux } \\
\text { Decrease }\end{array}$ & \multicolumn{3}{|c|}{ Approx. 11.75\% per Hour } \\
\hline $\mathbf{2 0}^{\circ}$ & $0800 \mathrm{hrs}$ & $0900 \mathrm{hrs}$ & $1000 \mathrm{hrs}$ \\
\hline $\begin{array}{c}\text { Solar } \\
\text { Declination } \\
\text { Angle }\end{array}$ & 27.93 & 41.21 & 53.61 \\
\hline $\begin{array}{c}\text { Average \% } \\
\text { Flux }\end{array}$ & 37.0 & 22.6 & 12.1 \\
\hline $\begin{array}{c}\text { Average Flux } \\
\text { Decrease }\end{array}$ & \multicolumn{3}{|c|}{ Approx. 12.45\% per Hour } \\
\hline
\end{tabular}

\section{Conclusions}

By comparing the findings between designs, $\mathrm{A}$ and $\mathrm{B}$, it can be determined that both designs allow for normal growth of crops (lettuce) in an urban setting with just natural lighting alone. However, the main difference between designs $\mathrm{A}$ and $\mathrm{B}$ is that the latter allows for a much higher surface area for whilst taking the same amount of vertical space. Design B allows for a higher yield due to the increase in surface area from the increase width of tray and at the same time, compensates the loss in irradiance due to shading by orientating the trays at an angle. By doing this seemingly small tweak, it optimises the amount of irradiance received by the trays, by taking advantage of reflected and diffused irradiance on the tray surfaces. This slight tweak permits the sunlight to reach further into the trays, ensuring that they receive adequate sunlight. This is done so with extremely restricted test parameters and it is certain that more optimistic results would be shown if plausible parameters are utilised for actual tests. Thereafter, by optimizing the solar irradiance through the assistance of the ray-tracing software, it can be illustrated that growing crops on trays in a confined urban setting is possible with following considerations:

Trays to be placed as close as possible to window due to fenestration.

Trays to be oriented at maximum 20 degrees if possible.

Ideally, top 2 trays could be perpendicular to the floor (at the sacrifice of crop space).

Underside of trays to be coated with high reflectivity material to maximise diffused and reflected irradiance.

Tray height to width ratio should be maintained near $1 / 3$. 
Trays should not be rotated but rather supported by strategically placed LED lights.

Finally, this paper could serve as learning purposes for basic educational entry point readers to the design configurating of solar based vertical farming. We used direct light point source in this TracePro software for simulations of flux intensities and may not directly applicable to more advanced VF designs such as the Agri-PV concept with the Daily Light Integral (DLI) / Photosynthetic Photon Flux Density (PPFD) (Zhang and Ng, 2021, inpress) over a full annual solar cycle and including the helio/photo-tropism in crops. The limitation of this work is that we have not conducted experimental validation.

\section{References}

Ahmed A, Khalid A, Soomro BA, Mohsin S, (2017) Impact of Solar Radiation on Building Envelope using Energy Plus Software, in 7th International Mechanical Engineering Congress, Karachi.

"American Society of Heating Refrigerating and Air-Conditioning," ASHRAE Handbook, 1985 Fundamentals.

"Climate, Sky and Solar/Shading Calculations," [Online].Available:

https://www.energyplus.net/sites/default/fil es/docs/site_v8.3.0/EngineeringReference/0 5Climate/index.html. [Accessed 112 2019].

"Comparing LED vs CFL vs Incandescent Light Bulbs," [Online]. Available: https://www.viribright.com/lumen-outputcomparing-led-vs-cfl-vs-incandescentwattage/.

"Do LED Lights Produce Heat? All About LED Heat Generation," [Online]. Available: https://lamphq.com/led-heat-generation/.

Germany_Aerospace_Center. (2012).

Feasibility Study: Vertical Farm EDEN.

Graamansa L, Baeza E, Dobbelsteen A, Tsafaras I, Stanghellini C, (2018) Plant factories versus greenhouses: Comparison of resource use efficiency, Agricultural Systems (160), pp. 31-43.
"Growing the future," [Online].Available: https://www.washingtonpost.com/graphics /2018/lifestyle/ledgrowing/?utm_term=.c3 $40878678 \mathrm{e} 3$.

"Grow Lights for Indoor Plants and Indoor Gardening: An Overview,'[Online]. Available:

https://modernfarmer.com/2018/03/growlights-for-indoor-plants-and-indoorgardening/.

"How Humidity Affects the Growth of Plants," [Online]. Available: https://www.polygongroup.com/enUS/blog/how-humidity-affects-thegrowth-of-plants/.

"How to Choose the Best Indoor Lighting for Plants," [Online]. Available: https://www.hgtv.com/outdoors/flowersand-plants/houseplants/how-to-choose-thebest-indoor-lighting-for-plants.

Jamil B, Khan MM, (2014) Estimation of Clear-Sky Solar Radiation using ASHRAE, ISSN 0974-3154, vol. 7, no. 3, pp. 227-236.

"June Solstice Sunrise Set Global Cities," [Online].Available:

https://www.washingtonpost.com/pbox.ph $\mathrm{p}$ ?url=http:/www.washingtonpost.com/blo gs/capital-weather-

gang/files/2013/06/June-solstice-sunriseset-global

cities.png\&w $=1484 \&$ op $=$ resizeopt $=1 \&$ filt $\mathrm{er}=$ antialias $\& \mathrm{t}=20170517$.

Kalantari F, Tahir OM, Joni RA, Fatemi E, (2017) Opportunities and challenges in sustainability of vertical farming: a review, Journal of Lanscape Ecology, vol. 11.

Liu X, (2016) Design of a Modified Shipping Container as Modular Unit for, The University of Arizona, Arizona, USA.

Maleki SAM, Hizam H, Gomes C, (2017) Estimation of Hourly, Daily and Monthly Global Solar Radiation on Inclined Surfaces: Models Re-Visited, Energies, vol. 10 , no. 134 .

Pankove JI, (1971) Optical Process In Semiconductors, Dover Publication.

Perez R, Seals R, Ineichen P, Stewart R, Menicucci D, (1987) A new simplified 
version of the perez diffuse, Solar Energy, vol. 39, no. 3, pp. 221-231.

"PV Modeling," [Online]. Available: https://pvpmc.sandia.gov/modelingsteps/1-weather-design-inputs/plane-ofarray-poa-irradiance/calculating-poairradiance/poa-sky-diffuse/perez-skydiffuse-model/. [Accessed 2812020 ].

"Singapore's Climate," [Online]. Available: http://www.weather.gov.sg/climateclimate-of-singapore/.

Sliney DH, (2016), "What is light? The visible spectrum and beyond," Eye (London), vol. 30 , no. 2, pp. 222-229.

Suszanowicz D, (2017) Internal heat gain from different light sources in the building," in E3S Web of Conferences 19.

"VertiCrop," [Online]. Available: http://grow.verticrop.com/verticalfarming/. [Accessed 112 2019].

Yadav AK, Chandel SS, (2014) Solar radiation prediction using Artificial Neural Network techniques: A review, Renewable and Sustainable Energy Reviews, vol. 33, pp. 772-781.

Zhang X, Ng EYK, (2021) Study of window transmission and sunlight guiding system in a solar-based vertical greenhouse, Carpathian Journal of Food Science and Technology. 13(1), in-press.

Zwinkels J, (2015) Light, Electromagnetic Spectrum, Springer Science+Business Media New York 2015, R. Luo (ed.), New York, 10.1007/978-3-642-27851-8_2041.

"80 Acres Farm," [Online]. Available: https://www.eafarms.com/\#OurFood. 